\title{
PREVISÃO DA INSOLVÊNCIA EMPRESARIAL UTILIZANDO REDES NEURAIS ARTIFICIAIS
}

\author{
FORECASTING BUSINESS INSOLVENCY USING \\ ARTIFICIAL NEURAL NETWORKS
}

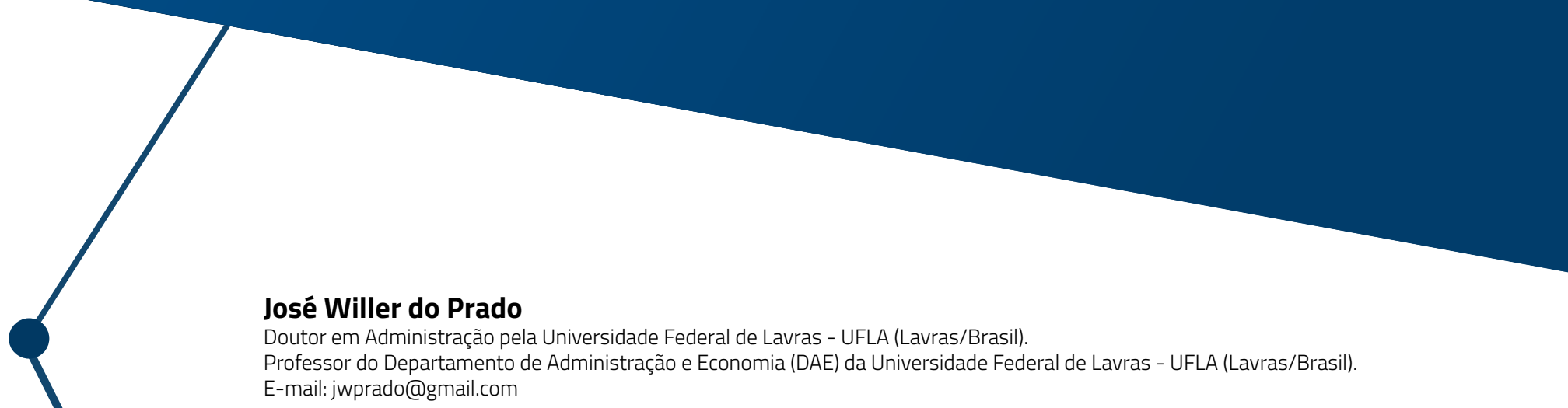

\section{Adriana Giarola Vilamaior}

Mestra em Ciências Contábeis pela Universidade Federal de Minas Gerais - UFMG (Belo Horizonte/Brasil).

Professora do Departamento de Gestão do Instituto Federal de Minas Gerais - IFMG/Campus Bambuí (Bambuí/Brasil).

E-mail: adriana.vilamaior@ifmg.edu.br

\section{Alyce Cardoso Campos}

Mestra em Administração pela Universidade Federal de Lavras - UFLA (Lavras/Brasil).

E-mail: alycecardosoc@yahoo.com.br

\section{Thaísa Barcellos Pinheiro do Nascimento}

Mestra em Administração pela Universidade Federal de Lavras - UFLA (Lavras/Brasil).

E-mail: thaisapinheiro35@gmail.com 


\section{RESUMO}

Nas negociações de crédito, o risco é um custo que está sempre presente e, portanto, precisa ser quantificado. Neste cenário, existem diversas ferramentas que se propõem à análise do crédito, algumas delas de ordem quantitativa. Neste sentido, esse artigo tem por objetivo propor um modelo capaz de prever a insolvência de empresas por meio da aplicação do modelo de redes neurais artificiais. 0 estudo é uma pesquisa exploratória de caráter quantitativo, aplicado à área financeira, utilizando-se o modelo tradicional e o modelo dinâmico de análise financeira. Com os resultados, obtiveram-se dois modelos: um contendo apenas as variáveis do modelo tradicional e outro com as variáveis do modelo tradicional e do modelo dinâmico de análise financeira. A comparação entre estes dois modelos de análise de crédito possibilitou verificar a contribuição das variáveis do modelo dinâmico para o modelo final. Os índices que mais contribuíram para acurácia do modelo proposto foram: Índice de Rentabilidade $\left(X_{5}\right)$ com 100\% de exatidão; Índice de Estrutura de Capitais $\left(X_{2}\right)$ com 98,9\% de acerto; e Índice do Modelo Dinâmico $\left(X_{8}\right)$ com $91 \%$ de precisão.

Palavras-chave: Análise de balanços. Risco de crédito. Insolvência. Modelos de previsão.

\section{ABSTRACT}

In credit negotiations the risk is a cost that is always present and therefore needs to be quantified. In this scenario, there are several tools that propose to credit analysis, some of them of quantitative order. In this sense, this article aims to propose a model capable of predicting the insolvency of companies by applying the artificial neural networks model. The study is exploratory research of quantitative character, applied to the financial area, using the traditional model and the dynamic model of financial analysis. The results obtained two models: one containing only the variables of the traditional model and another with the variables of the traditional model and the dynamic model of financial analysis. The comparison between these two models of credit analysis made it possible to verify the contribution of the variables of the dynamic model to the final model. The indexes that contributed most to the accuracy of the proposed model were: Profitability Index (X5) with 100\% accuracy; Capital Structure Index (X2) with 98.9\% accuracy and Dynamic Model Index (X8) with 91\% accuracy.

Keywords: Analysis of balance sheets. Credit risk. Insolvency. Forecasting models.. 


\section{INTRODUÇÃO}

Nas negociações de crédito, o risco é um custo que está sempre presente e, portanto, precisa ser quantificado. Segundo Assaf Neto (2010), a ideia de risco está associada à probabilidade de que ocorra determinado resultado em relação ao retorno esperado. Assim, está voltado para o futuro, revelando uma possibilidade de perda.

Neste cenário, existem diversas ferramentas que se propõem à análise do crédito, algumas delas de ordem quantitativa. As mais tradicionais na construção de modelos de risco de crédito são as técnicas de análise multivariada, como a análise discriminante e a regressão logística. Entretanto, novas técnicas de Inteligência Artificial têm chamado a atenção dos pesquisadores, entre elas, estão as redes neurais artificiais (TAM, 1991; CASTRO JUNIOR, 2003; LIMA et al., 2009; GOUVÊA; GONÇALVES; MANTOVANI, 2015).

A classificação do risco de crédito tem constituído uma ferramenta fundamental na concessão de crédito e seus métodos de previsão têm ganhado bastante repercussão (SILVA, 2008). Neste contexto, várias instituições financeiras têm buscado por estas ferramentas. Silva (2008) salienta que, na criação de um modelo de previsão de risco de crédito, é importante saber identificar qual dentre as técnicas estatísticas será mais eficiente para a modelagem dos dados, de forma a conseguir uma melhor previsão para a inadimplência.

Evidencia-se que as primeiras pesquisas neste campo (falência e risco de crédito) buscavam a discriminação dentro de um grupo de dados. Sendo alguns dos seus pioneiros os estudos realizados por Fisher (1936), The Use of Multiple Measurements in Taxonomic Problems e Durand (1941), Risk Elements in Consumer Installment Lending. Entretanto, as análises univariadas realizadas no final da década de 1950 foram substituídas assim que as pesquisas acadêmicas se voltaram para técnicas de modelagem de credit scoring no final da década de 1960 (SABATO, 2009). Os trabalhos seminais neste campo foram o Financial ratios predictors of failure de Beaver (1967) e Financial Ratios, Discriminant Analysis and the Prediction of Corporate Bankruptcy de Altman (1968). Esses dois estudos deram início à pesquisa com a multivariate discriminant analysis - MDA, a qual viria a se tornar bastante utilizada no campo, até Ohlson (1980) realizar um estudo chamado Financial ratios and the probabilistic prediction of bankruptcy, utilizando do modelo logit para a previsão de inadimplência, abrindo uma perspectiva para a utilização de outras metodologias no campo.

Sendo assim, o presente trabalho tem por objetivo propor um modelo capaz de prever a insolvência de empresas por meio da aplicação do modelo de redes neurais artificiais. Modelo este que deve ser 
capaz de identificar empresas (pessoas jurídicas) que estão próximas à falência, evitando, assim, a perda do capital concedido.

A pesquisa se justifica, dentre outros fatores, pela relevância do tema para o estudo das Finanças Corporativas e pelo papel fundamental que o crédito desempenha para as empresas que utilizam de capital de terceiros para manter suas atividades. Adiante, optou-se, no presente estudo, por utilizar tanto índices do modelo tradicional como do modelo dinâmico de análise financeira visando melhorar a acurácia na previsão. A escolha destas duas metodologias de análise financeira busca atingir a necessidade de integração do modelo tradicional com o modelo dinâmico de análise financeira, como proposto por Brasil e Brasil (2008). Adiante, pode contribuir para a aplicação das redes neurais em modelos de risco de crédito.

No intuito de direcionar o estudo, será utilizado o termo "solvente" apenas para instituições que têm uma boa saúde econômica e financeira e "insolvente" para representar empresas que passaram por dificuldades financeiras (não conseguiram quitar suas dívidas em tempo hábil) e entraram em processo de falência ou concordata (MATIAS, 1978; BRIGHAM; EHRHARDT, 2012).

O artigo está estruturado a partir desta introdução. Em seguida, é apresentado um referencial teórico que aborda análise financeira, o modelo tradicional e o dinâmico. A metodologia se trata de uma pesquisa exploratória de caráter quantitativo. Com os resultados, obtiveram-se dois modelos: um contendo apenas as variáveis do modelo tradicional e outro com as variáveis do modelo tradicional e do modelo dinâmico de análise financeira. A comparação entre estes dois modelos de análise de crédito possibilitou verificar a contribuição das variáveis do modelo dinâmico para o modelo final. Por último, podem ser vistas as considerações finais e as referências utilizadas para a construção deste trabalho.

\section{REFERENCIAL TEÓRICO}

\subsection{DEFINIIÇÕES DO CRÉDITO, RISCO E ANÁLISE}

Segundo Faria e Santos (2014), um sistema de crédito desenvolvido está diretamente relacionado com o grau de desenvolvimento da economia de um país. Neste contexto, devido à importância do crédito para a economia como um todo, existem vários autores que fazem considerações sobre o crédito. Uma das definições mais encontradas em trabalhos sobre crédito é de autoria de Schrickel (2000, p. 25), que assim define crédito como:

[...] todo ato de vontade ou disposição de alguém de destacar ou ceder, temporariamente, 


\section{Gestãoe \\ Desenvolvimento}

e-ISSN: 2446-6875

p-ISSN: $1807-5436$

parte de seu patrimônio a um terceiro, com a expectativa de que esta parcela volte a sua posse integralmente, depois de decorrido o tempo estipulado. Essa parte do patrimônio pode ser materializada por dinheiro (empréstimo monetário) ou bens (empréstimo para uso, ou venda com pagamento parcelado, ou a prazo).

Como salienta Timm (2005), os tomadores de crédito buscam recursos financeiros junto a instituições financeiras para suprir suas necessidades operacionais. Para Assaf Neto e Silva (2012), crédito diz respeito à troca de bens presentes por bens futuros. 0 autor complementa que, quando uma empresa concede crédito, troca produtos por uma promessa de pagamento futuro. Por outro lado, uma empresa que obtém crédito recebe produtos e assume o compromisso de efetuar o pagamento no futuro.

Portanto, na concessão de crédito, a empresa terá de responder "sim" ou "não" ao cliente e, caso a resposta seja positiva, deverá responder "até quando". Novamente, o critério norteador da decisão será a maximização da riqueza da empresa, levando-se também em consideração o risco envolvido. (ASSAF NETO; SILVA, 2012, p. 140).

Quando o tema abordado é crédito, logo surgem observações sobre risco ou sobre incertezas nas operações. Para Silva (2008, p. 56), em finanças, o conceito de risco e o conceito de incerteza são utilizados de formas diferentes, a saber:

(a) Risco: existe quando o tomador de decisões pode embasar-se em probabilidades objetivas para estimar diferentes resultados, de modo que sua expectativa se baseia em dados históricos e, portanto, a decisão é tomada a partir de estimativas julgadas aceitáveis pelo tomador de decisão. (b) Incerteza: ocorre quando o tomador não dispõe de dados históricos acerca de um fato, o que poderá exigir que o tomador de decisões faça uma distribuição probabilística subjetiva, isto é, baseado em sua sensibilidade pessoal.

Para Assaf Neto (2010), toda vez que se possa quantificar a incerteza por meio de uma distribuição de probabilidades dos diversos resultados previstos, diz-se que está sendo tomada uma decisão sob situação de risco. Para Carvalho (2007), o risco transcorre sempre de uma tomada de decisão relacionada com o futuro, que pode ser determinada pela diferença de probabilidade/improbabilidade, ocasionando frustrações por eventos insertos. Neste sentido, o risco pode ser interpretado como a capacidade de se mensurar a incerteza de uma decisão, devido ao conhecimento das probabilidades associadas à ocorrência de determinados resultados. 
Neste cenário, as técnicas estatísticas multivariadas utilizadas na concessão de crédito têm sido consideradas como ferramentas bastante úteis para o reconhecimento da inadimplência na administração do crédito.

Como salienta Pereira, Domínguez e Ocejo (2007), a partir dos trabalhos pioneiros de Beaver (1967) e Altman (1968), vem sendo crescente o número de pesquisadores que se interessam por esta temática. Os autores afirmam ainda que os pesquisadores, cada vez mais, têm procurado técnicas e ferramentas alternativas para incorporar, nos modelos elaborados, maior utilidade e precisão.

Neste artigo estão especialmente as técnicas de redes neurais artificiais que vêm apresentando boa acurácia nas previsões em vários estudos desenvolvidos. Entre esses, pode-se citar Tam (1991), que apresentou uma abordagem de rede neural para previsão de falências bancárias, comparando seu desempenho com modelos existentes. Os resultados empíricos de Tam (1991) mostram que os modelos de redes neurais são um instrumento competitivo para avaliar a condição financeira de um banco.

Castro Junior (2003) comparou modelos estatísticos usando as técnicas de Análise Discriminante Linear, Regressão Logística e Redes Neurais Artificiais, a fim de investigar qual delas oferece os melhores resultados na previsão de falência. Neste estudo, as Redes Neurais demostraram um desempenho superior às outras técnicas. Lima et al. (2009) apresentaram uma aplicação de redes neurais na concessão de crédito ao consumidor, e os resultados demostraram que as redes neurais representam uma próspera técnica para análise de crédito ao consumidor. Gouvêa, Gonçalves e Mantovani (2015) compararam as técnicas de regressão logística e redes neurais. Nesse trabalho, os dois modelos testados apresentaram estatísticas de desempenho satisfatórias na predição de credit scoring.

Mesmo assim, segundo Silva (2008), devem-se tomar alguns cuidados, uma vez que é extremamente difícil cercar todos os possiveis fatores que influem no perfil dos tomadores de crédito. Silva (2008) ressalta que o uso de métodos quantitativos tem sido muito divulgado, o que tem levado muitas instituições a uma corrida em busca dessas técnicas para avaliação do risco de crédito dos clientes, devido a sua contribuição para o processo de análise.

Alguns dos trabalhos de relevância realizados dentro da temática do risco de crédito no país são: Kanitz (1974); Elizabetsky (1976); Matias (1978); Altman, Baidya e Dias (1979); Silva (2008); Sanvicente e Minardi (1998); Mário (2002); Castro Junior (2003) e Carvalho (2004). Desde de 1974, com o trabalho pioneiro de Kanitz, a análise de risco de crédito no Brasil vem crescendo.

\subsection{ANÁLISE FINANCEIRA}

Brasil e Brasil (2008) salientam que, tradicionalmente, a análise financeira parte de uma visão estática da organização, que procura responder se a empresa terá condições de saldar seus compromissos, no 


\section{Gestãoe \\ Desenvolvimento}

e-ISSN: 2446-6875

p-ISSN: 1807-5436

caso de encerramento de suas atividades. Ou seja, a ênfase recai sobre os aspectos relativos à solvência da empresa, em um sistema que parou de funcionar, medidos pelos índices de liquidez.

Já por uma perspectiva do enfoque dinâmico da análise financeira, pode-se partir do princípio que a empresa é um "organismo vivo", inserido em um ambiente constantemente mutável. Volta-se para os aspectos financeiros de liquidez, que procura responder se a empresa tem capacidade de cumprir com suas obrigações, mantendo-se em funcionamento e permitindo ao gestor tomar medidas durante o processo (BRASIL; BRASIL, 2008).

A visão estática da análise tradicional é baseada na solvência da empresa (via 1), e a visão sistêmica da análise dinâmica é focada na liquidez empresarial (via 2). Estas duas visões e sua respectiva complementariedade (integração) são desejadas, como sugerem Brasil e Brasil (2008). Esta necessidade de integração entre os dois modelos pode ser mais bem visualizada na Figura 1.

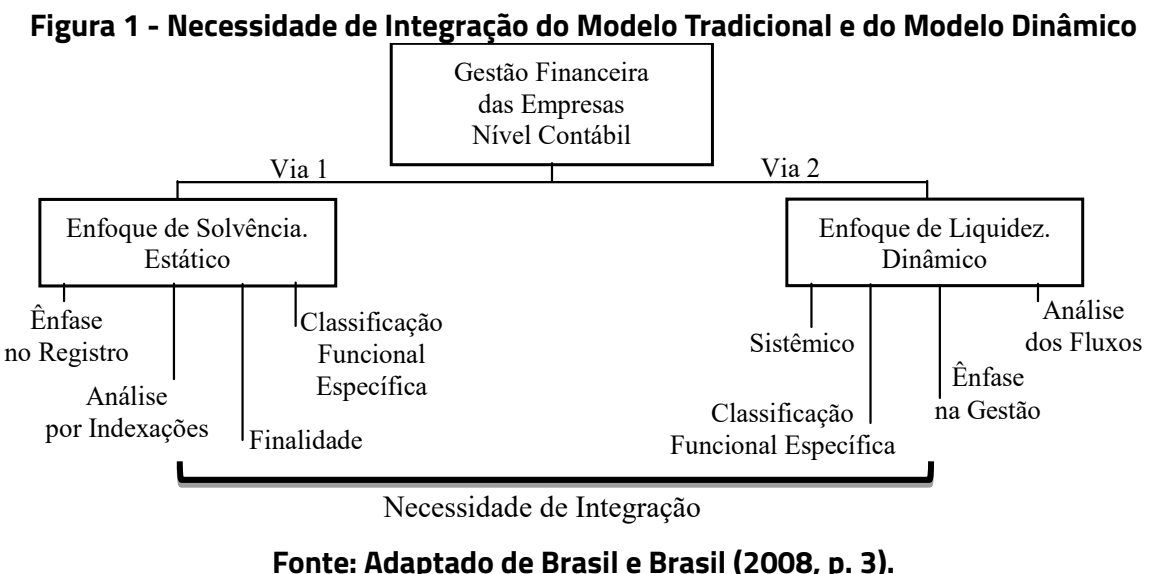

Dentro da análise financeira, Brigham e Ehrhardt (2012) frisam que os indicadores financeiros são desenvolvidos para extrair informações relevantes sobre as organizações, que podem não ser óbvias, se o analista simplesmente examinar as demonstrações financeiras de uma empresa. Mas, quanto à previsão de insolvência, a literatura financeira não estabelece de forma definitiva quais são os melhores indicadores a serem utilizados. Os índices são utilizados de forma recorrente por vários pesquisadores, contudo, sua escolha depende, normalmente, da disponibilidade de dados e da intuição do pesquisador (MARTINS, 2007). 


\subsubsection{Modelo tradicional}

Matias (1978) observa que a análise financeira tradicional está consagrada no meio bancário empresarial quando a pauta é a concessão de crédito. Contudo, afirma que existe um excesso de informações, que são pouco relevantes na análise das empresas. Outro fator salientado pelo autor é o enorme número de índices financeiros, que tornam as análises complexas e desviam-se do objetivo básico que é identificar boas e más empresas no menor tempo e a um baixo custo.

O enfoque tradicional confronta ativos e passivos circulantes, objetivando descobrir a capacidade de pagamento de uma determinada empresa e sua capacidade de sobrevivência, ao longo do tempo. Isto é, a capacidade de pagamento das obrigações da empresa está vinculada ao fato de esta ter de alienar seu ativo circulante. Segundo Assaf Neto e Silva (2012), tais indicadores têm a sua importância, mas não costumam fornecer informações ao analista sobre as efetivas necessidades de capital de giro e também a posição financeira corrente e esperada da empresa.

Fleuriet, Kehdy e Blanc (1978; 2003) argumentam que a estrutura da apresentação tradicional agrupa as diversas contas, de acordo com dois critérios de classificação. O primeiro distingue, verticalmente, as contas do ativo, que representam as aplicações, e as contas do passivo, que representam a origem destas aplicações. O segundo agrupa, horizontalmente, as contas do ativo e do passivo, de acordo com os prazos destas contas, numa ordem de disponibilidade decrescente. Adiante, Fleuriet, Kehdy e Blanc (1978; 2003) criticam o modelo tradicional, no sentido de que a classificação horizontal mede, de forma errônea, os prazos de permanência, durante os quais os fundos ficam à disposição da empresa. Os autores observam que certas contas do ativo e passivo se renovam constantemente, à medida que se desenvolvem as operações da empresa. Este fato constitui a base para uma nova classificação horizontal e o surgimento do modelo dinâmico.

\subsubsection{Modelo dinâmico}

O Modelo dinâmico surge da importante contribuição dada por Michel Fleuriet, Ricardo Kehdy e Georges Blanc, em 1978, através da reclassificação dos grupos de contas do Balanço Patrimonial. Esta reclassificação traz novos quocientes, gerados a partir dos estudos focados na dinâmica do capital de giro.

De acordo com Fleuriet, Kehdy e Blanc (2003, p. 7), "para uma melhor compreensão do modelo de análise financeira que se pretende definir, as contas do ativo e do passivo devem ser consideradas em relação à realidade dinâmica das empresas, em que as contas são classificadas de acordo com o seu ciclo". Contudo, a implementação do Modelo Dinâmico proposto por Fleuriet, Kehdy e Blanc (1978) pressupõe a reclassificação das demonstrações financeiras, que são elaboradas e divulgadas pelas empresas e 
fixadas pela Lei $n^{\circ}$ 6.404/76, no Art. 178 e pela Lei $n^{\circ}$ 11.638, de 28 de dezembro de 2007, para um padrão completamente dinâmico e funcional, com o objetivo de atender a administração financeira da organização de forma satisfatória.

Dessa nova segmentação do Balanço Patrimonial, surgem as variáveis do Modelo Dinâmico, que são: Necessidade de Capital de Giro (NCG), Capital de Giro (CDG) e Saldo de Tesouraria (T), estes novos indicadores são utilizados na análise econômico-financeira das empresas não mais de forma estática. Além de que, com base nestas três variáveis, surge a análise do Efeito Tesoura.

O cálculo da Necessidade de Capital de Giro (NCG) mede a quantidade de investimentos operacionais cíclicos, que são necessários para manter as operações da empresa dentro do seu ciclo operacional, de forma que esta consiga financiar suas atividades operacionais (FLEURIET; KEHDY; BLANC, 1978; 2003; ASSAF NETO; SILVA, 2012).

Necessidade de Capital de Giro = Ativo Circulante Operacional - Passivo CirculanteOperacional

$$
N C G=A C O-P C O
$$

Denomina-se Capital de Giro (CDG) a diferença entre o passivo permanente e o ativo permanente. O Ativo Permanente (AP) é formado por contas não cíclicas do ativo e o Passivo Permanente (PP) são as contas não cíclicas do passivo.

$$
\begin{gathered}
\text { Capital de Giro }=\text { Passivo Permanente }- \text { Ativo Permanente } \\
\qquad C D G=P P-A P
\end{gathered}
$$

Fleuriet, Kehdy e Blanc (1978; 2003) denominam o Saldo de Tesouraria (T) a partir das contas do "ativo errático" e do "passivo errático", que nada mais são do que as contas do "ativo financeiro" e do "passivo financeiro".

$$
\begin{gathered}
\text { Saldo de Tesouraria }=\text { Ativo Financeiro }- \text { Passivo Financeiro } \\
\qquad T=C D G-N C G
\end{gathered}
$$

A reclassificação do Balanço Patrimonial sugerida por Fleuriet, Kehdy e Blanc, em 1978, dentro de seu Modelo Dinâmico, permite ao analista avaliar a ocorrência do Efeito Tesoura. Os autores acrescentam que a diretoria financeira deve acompanhar a evolução do Saldo em Tesouraria, a fim de evitar que este permaneça constantemente negativo e crescente, gerando um excesso de empréstimos de curto prazo, que poderá levar a empresa a um estado de insolvência. 


\section{Gestãoe \\ Desenvolvimento}

e-ISSN: 2446-6875

p-ISSN: 1807-5436

Sanvicente e Minardi (1998) observam que a Necessidades de Capital de Giro (NCG) e Saldo em Tesouraria (T) são dois componentes do Capital de Giro Líquido, que é um fator relevante para prever falências no Brasil. Atentos ao fato de que várias empresas brasileiras enfrentam situações de insolvência em decorrência do Efeito Tesoura, eles sugerem utilizar NCG e T para avaliar a liquidez, no intuito de melhorar a acurácia da avaliação da insolvência empresarial.

O comportamento do Efeito Tesoura é representado por um crescimento mais que proporcional da Necessidade de Capital de Giro em relação ao Capital de Giro, tornando o Saldo em Tesouraria negativo, o que pode ser mais bem observado na Figura 2.

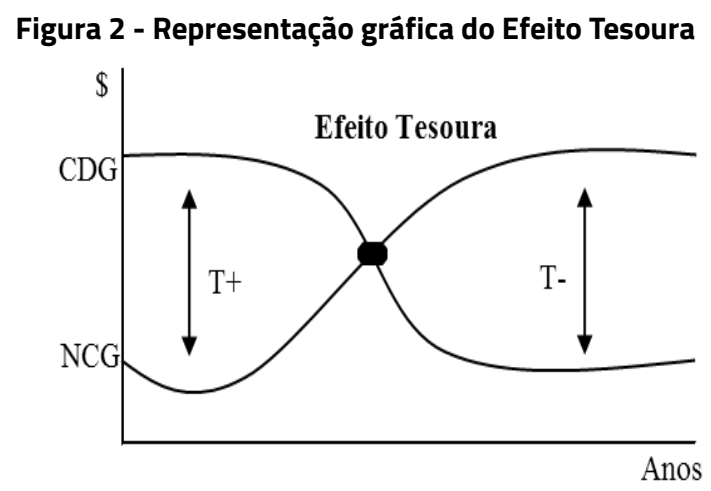

Fonte: Adaptado de Carvalho (2004, p. 65).

Brasil e Brasil (2008), ainda dentro desta mesma corrente teórica, afirmam que a patologia da administração do Saldo em Tesouraria é o Efeito Tesoura que surge de uma excessiva dependência de empréstimos de curto prazo, o que torna crítica a liquidez da empresa. Os autores frisam que qualquer corte de crédito que ocorra por efeito de desabastecimento da economia e, portanto, das vendas, pode levar a empresa a um estado de insolvência rapidamente, pois o atraso com os fornecedores é inevitável nestas condições.

Sendo assim, a análise do Efeito Tesoura, conforme recomendado por Assaf Neto e Silva (2012), é mais apropriada para identificar problemas futuros de insolvência dentro das organizações.

\section{METODOLOGIA}

O presente estudo é uma pesquisa exploratória de caráter quantitativo, por se tratar de uma modelagem matemática computacional aplicada à área financeira, na qual foi utilizado o software SPSS (Statistical Package for Social Sciences). Os dados utilizados no trabalho são secundários e retirados de 


\section{Gestãoe \\ Desenvolvimento}

e-ISSN: 2446-6875

p-ISSN: $1807-5436$

Carvalho (2004). Assim, a amostra, colhida no período de 2003, refere-se a empresas do setor comercial (sendo 50 solventes e 50 insolventes).

Observa-se que a segmentação da amostra por setor de atuação (setor comercial) tem como único objetivo tentar melhorar a acurácia do modelo. Como elucida Silva (2008), a escolha da amostra constituise numa das partes mais importantes para a criação de um modelo, sendo a escolha de um ramo, entre os diversos ramos de atividade, um dos fatores a ser considerado.

Neste sentido, foram utilizadas duas amostras para a criação do presente modelo: uma contendo empresas solventes e outra contendo empresas insolventes. Através destes dois grupos (solvente e insolvente), foi possivel criar uma modelagem capaz de separar, em um momento futuro, empresas solventes de empresas insolventes, a partir de suas características.

Neste sentido, para a criação do modelo de previsão de risco de crédito por meio de redes neurais artificiais foram utilizados tanto indicadores (variáveis) econômico-financeiros do modelo tradicional de análise financeira como indicadores do modelo dinâmico de análise financeira. Na sequência, o tópico 3.1 apresenta a escolha das variáveis do modelo tradicional, o tópico 3.2 aborda a escolha das variáveis do modelo dinâmico, e por fim, o tópico 3.3 traz a técnica das redes neurais artificiais para criação do modelo de previsão de risco de crédito.

\subsection{A ESCOLHA DAS VARIÁVEIS DO MODELO TRADICIONAL}

Para representar o modelo tradicional de análise financeira, foram utilizados os indicadores desenvolvidos por Silva (2012). Neste trabalho, o autor utilizou, no desenvolvimento de modelos de previsão de insolvência, um total de 85 índices.

No presente estudo, foram utilizadas as seis variáveis definidas por Silva (2012), como sendo as mais relevantes para classificação de crédito de empresas comerciais, e que apresentaram um melhor escore discriminante para a previsão da insolvência no próximo exercício, um ano antes da falência (Tabela 1). 
Tabela 1 - Variáveis do Modelo Tradicional de Análise Financeira

\begin{tabular}{|c|c|c|}
\hline Índices & VARIÁVEIS DO MODELO TRADICIONAL & \\
\hline $\begin{array}{l}\text { Indicador de } \\
\text { estrutura }\end{array}$ & $X_{1}=\frac{\text { Reservas }+ \text { Lucros Suspensos }}{\text { Ativo Total }}$ & (4) \\
\hline $\begin{array}{l}\text { Indicador de } \\
\text { estrutura }\end{array}$ & $X_{2}=\frac{\text { Disponivel }}{\text { AtivoTotal }}$ & (5) \\
\hline Índice de liquidez & $X_{3}=\frac{\text { Ativo Circulante }- \text { Disponivel }- \text { Passivo Circulante }+ \text { Financiamentos }+ \text { Duplicatas Descontadas }}{\text { Vendas }}$ & (6) \\
\hline Índice de retorno & $X_{4}=\frac{\text { Lucro Operacional }+ \text { Despesas Financeiras }}{\frac{\text { Ativo Inicial }+ \text { Ativo Final }}{2}-\frac{\text { Investimentos Inicial }+ \text { Investimentos Final }}{2}}$ & (7) \\
\hline Índice de retorno & $X_{5}=\frac{\text { LucroOperacional }}{\text { Lucro Bruto }}$ & (8) \\
\hline Índice de retorno & 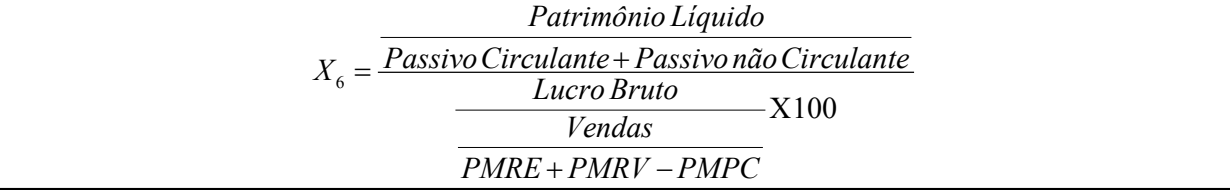 & (9) \\
\hline
\end{tabular}

\section{Fonte: Adaptado de Carvalho (2004) e Silva (2012).}

\subsection{A ESCOLHA DAS VARIÁVEIS DO MODELO DINÂMICO}

Já no que diz respeito ao modelo dinâmico de análise financeira, serão utilizados os índices testados por Sanvicente e Minardi (1998) e por Carvalho (2004). Estes estudos partem das observações realizadas por Assaf Neto e Silva (2012), em que os autores, embasados pelos estudos de Fleuriet, Kehdy e Blanc (1978; 2003), salientam a importância do modelo dinâmico e afirmam que a dinâmica do Efeito Tesoura é a mais apropriada para identificar problemas futuros de insolvência.

Como demonstrado anteriormente, tanto Carvalho (2004) quanto Sanvicente e Minardi (1998) utilizam a variável $X_{7}$ como um indicador de liquidez, que, ao relacionar ativos e passivos operacionais com o ativo total, retrata a Necessidade de Capital de Giro da empresa. Outro indicador de liquidez abordado 


\section{Gestãoe \\ Desenvolvimento}

e-ISSN: 2446-6875

p-ISSN: $1807-5436$

pelos autores, em seus respectivos trabalhos, é a variável $X_{8^{\prime}}$ que representa o Saldo de Tesouraria da empresa (Tabela 2).

Tabela 2 - Variáveis do Modelo Dinâmico de Análise Financeira

\begin{tabular}{lcc}
\hline \multicolumn{1}{c}{ Índices } & VARIÁVEIS DO MODELO DINÂMICO \\
\hline $\begin{array}{c}\text { Índice de } \\
\text { liquidez }\end{array}$ & $X_{7}=\frac{\text { Ativo Circulante Operacional -Passivo Circulante Operacional }}{\text { Ativo Total }}$ \\
\hline $\begin{array}{c}\text { Índice de } \\
\text { liquidez }\end{array}$ & $X_{8}=\frac{\text { Ativo Circulante Financeiro - Passivo Circulante Financeiro }}{\text { Ativo Total }}$ \\
\hline
\end{tabular}

Fonte: Adaptado de Fleuriet, Kehdy e Blanc (1978; 2003) e Carvalho (2004).

A escolha das variáveis $X_{7}$ e $X_{8}$ representando o modelo dinâmico, juntamente com as variáveis $X_{1^{\prime}}$ $X_{2^{\prime}} X_{3^{\prime}} X_{4^{\prime}} X_{5}$ e $X_{6}$ do modelo tradicional, buscam resolver a necessidade de integração (complementaridade) entre os dois modelos de análise financeira, como recomendado por Brasil e Brasil (2008).

\subsection{REDES NEURAIS ARTIFICIAIS}

O artigo pioneiro de Redes Neurais Artificiais publicado foi o de Warren McCulloch e Walter Pitts, em 1943. Warren McCulloch foi um psiquiatra e neuroanatomista por treinamento que, durante 20 anos, refletiu sobre a representação de um evento no sistema nervoso. Walter Pitts foi um matemático que, em 1942, se associou a Warren McCulloch (HAYKIN, 2001). No ano seguinte, McCulloch e Pitts (1943) publicaram um artigo intitulado A Logical Calculus of the Ideas Immanent in nervous Activity, onde apresentam uma sofisticada discussão sobre as redes lógicas de neurônios artificiais denominados de MCP (devido a McCulloch e Pitts), que unificavam os estudos da neurofisiologia e da lógica matemática. Segundo McCulloch e Pitts, o seu modelo de neurônio segue a lei do "tudo ou nada", que é um caráter da atividade nervosa, sendo que eventos neurais e as relações entre eles podem ser tratados por meio da lógica proposicional.

Haykin (2001) apresenta a unidade fundamental de processamento de uma rede neural artificial, o neurônio artificial. Os neurônios artificiais podem ser classificados em vários modelos. Entretanto, estes se diferenciam basicamente pelo tipo de entrada (binária ou contínua), tipo de saída e função de ativação que será utilizada. A representação de um neurônio base para o projeto de redes neurais (artificiais) é apresentado na Figura 3. 


\section{Gestãoe \\ Desenvolvimento}

e-ISSN: 2446-6875

p-ISSN: $1807-5436$

Figura 3 - Modelo não linear de um neurônio

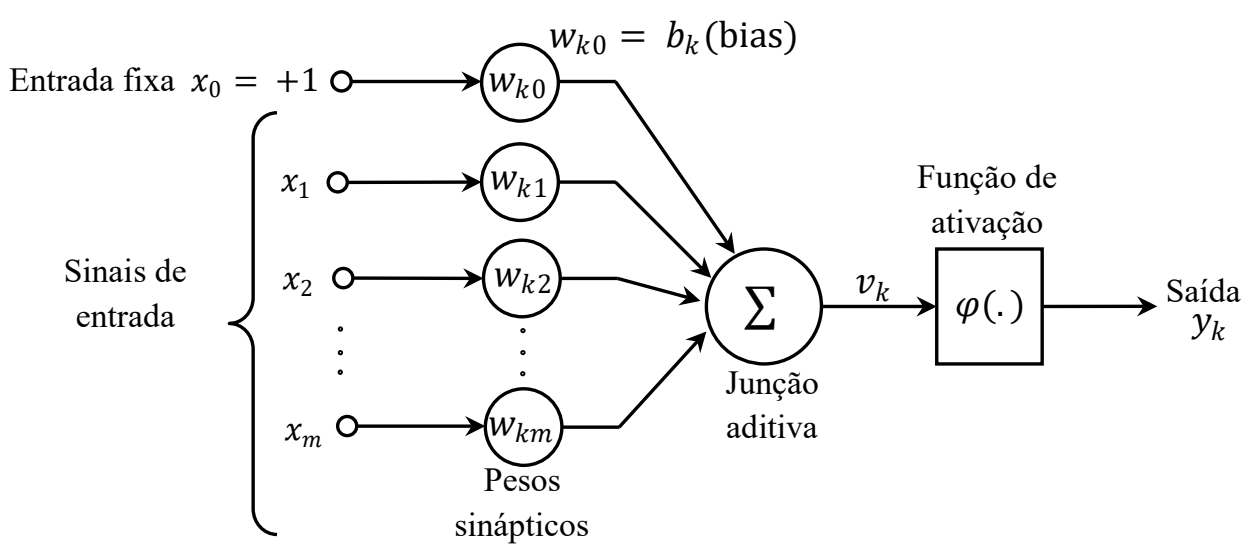

Fonte: Adaptado de Haykin (2001, p. 38).

Como observado por Haykin (2001), na Figura 3, pode-se visualizar três elementos básicos do modelo neural:

1. Um conjunto de sinapses, cada uma caracterizada por um peso próprio. Sendo cada sinal $x_{j}$ na entrada da sinapse $j$ ligada ao neurônio $k$ e multiplicada pelo peso sináptica $w_{k \jmath}$ onde o primeiro subscrito indica o neurônio ( $k$ ) em questão e o segundo se refere ao terminal de entrada da sinapse (j), à qual o peso se refere.

2. Uma função soma que realiza o somatório de todos os sinais de entrada, ponderados pelos seus respectivos pesos.

3. Uma função de ativação ( $\varphi$ é a função de ativação do neurônio $k$ ), para decidir acerca da transmissão do sinal (impulso) de um neurônio. Esta função também restringe a amplitude de sinal de saída a um valor finito. Normalmente, este é escrito em intervalo unitário fechado $[0,1]$ ou alternativamente $[-1,1]$ e $y_{k} e ́$ o sinal de saída do neurônio.

Para a construção de um modelo de redes neurais artificiais, devem ser consideradas três características fundamentais, a saber: a arquitetura, que dá forma à rede (organização da rede em camadas); o algoritmo de aprendizado, mais eficaz para o modelo proposto (método para determinação dos pesos); e a função de ativação (que estipula os dados estipulados) (HAYKIN, 2001).

Para se classificar em solvente ou insolvente, no presente trabalho, foi utilizada a rede do tipo perceptron de múltiplas camadas (MLP - Multi Layer Perceptron), como uma arquitetura feedforward, que seguem um fluxo para frente, a partir da camada de entrada até a camada de saída.

A camada de entrada conteve os preditores que no presente caso são as variáveis $X_{1^{\prime}} X_{2^{\prime}} X_{3^{\prime}} X_{4^{\prime}} X_{5^{\prime}}$ $X_{6^{\prime}} X_{7}$ e $X_{8}$ indices econômico-financeiros de empresas brasileiras, que representaram o modelo tradicional 


\section{Gestãoe \\ Desenvolvimento}

e-ISSN: 2446-6875

p-ISSN: 1807-5436

e o modelo dinâmico de análise. A camada de saída contém as respostas, duas classes, solvente ou insolvente, referente à situação da empresa.

Entretanto, o número de valores de entrada (preditores) e o tipo e quantidade de saídas possíveis, a quantidade de neurônios na camada oculta é definida pelo processo de tentativa e erro. Sobre este assunto, Braga, Carvalho e Ludermir (2011, p. 71) afirmam que "a determinação do número de neurônios é, na verdade, o problema mais fundamental em aprendizado de redes neurais, e motiva boa parte das pesquisas na área".

A função de ativação utilizada aqui é a sigmoide (logsig - função logística sigmoide), para a camada oculta e para a camada de saída, tendo em consideração que, no perceptron de múltiplas camadas, devemse utilizar funções de ativação não lineares nas camadas intermediarias, possibilitando que as camadas sucessivas sejam capazes de resolver problemas de maior ordem, no espaço de entrada, conforme salientado por Braga, Carvalho e Ludermir (2011).

A configuração básica utilizada para a criação da rede neural artificial pode ser observada na tabela 3, que disponibiliza, em termos gerais, as características da modelagem neste estudo.

Tabela 3 - Hipótese de configuração da Rede Neural

\begin{tabular}{ll}
\hline \multicolumn{2}{l}{ HIPÓTESE DE CONFIGURAÇÃO DA REDE NEURAL } \\
\hline Aplicação & Classificação \\
\hline Rede neural artificial & MLP \\
\hline Arquitetura & feedforward \\
\hline Tipo de aprendizagem & supervisionada \\
\hline Algoritmo de treinamento & back-propagation \\
\hline Número de dados preditores & 8 \\
\hline Número de camadas ocultas & 1 \\
\hline Número de neurônios ocultos & "X" \\
\hline Função de ativação utilizada na camada escondida & sigmoide (logsig) \\
\hline Número de neurônios de saída & 2 \\
\hline Função de ativação utilizada na camada saída & sigmoide (logsig) \\
\hline
\end{tabular}

Fonte: Elaborado pelo autor.

Conforme Braga, Carvalho e Ludermir (2011) ressaltam, o poder de classificação da rede neural pode ser avaliado, submetendo a rede a padrões diferentes daqueles utilizados no treinamento. Assim, neste trabalho foi observado o número de acertos realizados pela rede (classificador) para um conjunto 
de padrões cujas classes sejam conhecidas. Para avaliar o desempenho da rede, devem-se apresentar as porcentagens de classificações corretas (taxa de acerto).

\section{RESULTADOS E DISCUSSÃO}

Após vários testes (tentativa e erro), chegou-se a dois modelos de avaliação da insolvência empresarial. O primeiro modelo foi criado a partir tanto das variáveis do modelo tradicional quanto das variáveis do modelo dinâmico de análise financeira e será denominado como Modelo - MT\&D. O segundo modelo foi criado somente com as variáveis do modelo tradicional e será apresentado como Modelo - MT. Cabe ressaltar que estas foram as melhores configurações encontradas para a criação do Modelo - MT\&D e do Modelo - MT, após serem avaliadas diversas configurações possíveis. Acredita-se, entretanto, que se tenha encontrado a melhor configuração para a criação dos presentes modelos.

Na Tabela 4, é apresentada a divisão da amostra em amostra de treinamento e amostra de validação. Tanto no caso do Modelo - MT\&D quanto do Modelo - MT, a divisão da amostra foi a mesma para treinamento e para validação, sendo 68\% dos casos para treinamento e $32 \%$ dos casos para validação, não ocorrendo a exclusão de nenhum caso.

\begin{tabular}{|c|c|c|c|c|c|}
\hline & & \multicolumn{2}{|c|}{ MODELO - MT\&D } & \multicolumn{2}{|c|}{ MODELO - MT } \\
\hline & & $\mathbf{N}$ & Porcentagem & $\mathbf{N}$ & Porcentagem \\
\hline \multirow[t]{2}{*}{ Amostra } & Treinamento & 68 & $68 \%$ & 68 & $68 \%$ \\
\hline & Validação & 32 & $32 \%$ & 32 & $32 \%$ \\
\hline Válido & & 100 & $100 \%$ & 100 & $100 \%$ \\
\hline Excluídos & & 0 & $0 \%$ & 0 & $0 \%$ \\
\hline Total & & 100 & $100 \%$ & 100 & $100 \%$ \\
\hline
\end{tabular}

Fonte: Dados da pesquisa.

Grande parte da configuração da rede neural pode ser observada na Tabela 5 (Informações de rede), onde se encontram diversas especificações. Observa-se que as covariáveis (número de unidades) representam os índices econômico-financeiros, sendo oito (8) para o Modelo - MT\&D e seis (6) para o Modelo - MT.

Quanto à arquitetura, foi definida apenas uma camada oculta para cada um dos modelos. Entretanto, cabe ressaltar que outras arquiteturas foram testadas sem maiores sucessos. Já a camada oculta com quatro neurônios (unidades) foi a que representou maior poder de classificação nos testes realizados para 


\section{Gestãoe \\ Desenvolvimento}

e-ISSN: 2446-6875

p-ISSN: $1807-5436$

os dois modelos. A função de ativação dos modelos utilizada foi a função sigmoide, tanto na camada oculta como na camada de saída, por apresentar melhor desempenho do que outras funções testadas.

Tabela 5 - Informações de rede

\begin{tabular}{|c|c|c|c|c|}
\hline & & & MODELO - MT\&D & MODELO - MT \\
\hline \multirow[t]{10}{*}{ Camada de entrada } & \multirow{8}{*}{ Covariáveis } & 1 & $\mathrm{X} 1$ & $x 1$ \\
\hline & & 2 & $x 2$ & $x 2$ \\
\hline & & 3 & X3 & X3 \\
\hline & & 4 & $X 4$ & $\times 4$ \\
\hline & & 5 & $\times 5$ & $\times 5$ \\
\hline & & 6 & $x 6$ & $x 6$ \\
\hline & & 7 & $x 7$ & \\
\hline & & 8 & X8 & \\
\hline & \multicolumn{2}{|l|}{ Número de unidades } & 8 & 6 \\
\hline & \multicolumn{2}{|c|}{$\begin{array}{l}\text { Método de reescalonamento para } \\
\text { covariáveis }\end{array}$} & Padronizado & Padronizado \\
\hline \multirow[t]{3}{*}{ Camadas ocultas } & \multicolumn{2}{|c|}{ Número de camadas ocultas } & 1 & 1 \\
\hline & \multicolumn{2}{|c|}{ Número de unidades na camada oculta $1^{\text {a }}$} & 4 & 4 \\
\hline & \multicolumn{2}{|l|}{ Função de ativação } & Sigmoide & Sigmoide \\
\hline \multirow[t]{3}{*}{ Camada de saída } & Variáveis dependentes & 1 & Classg & Classg \\
\hline & \multicolumn{2}{|l|}{ Número de unidades } & 2 & 2 \\
\hline & \multicolumn{2}{|l|}{ Função de ativação } & Sigmoide & Sigmoide \\
\hline
\end{tabular}

Fonte: Dados da pesquisa.

A estrutura da rede neural é de grande valia para entender a arquitetura geral da rede. Haykin (2001) e Braga, Carvalho e Ludermir (2011) frisam que o perceptron de multicamadas (MLP) é uma função de preditores (variáveis independentes ou insumos) que minimizam o erro de predição das variáveis-alvo (saídas).

Na Figura 4, pode-se observar a estrutura pré-definida de arquitetura feedforward para os dois modelos criados com as seguintes características, a saber: a camada de entrada contém os preditores, índices econômico-financeiros, sendo que, no Modelo - MT\&D, encontram-se as variáveis $X_{1}$ até a $X_{8}$ e, no Modelo - MT, encontram-se apenas as variáveis do modelo tradicional de $X_{1}$ a $X_{6}$. Para a camada oculta, utilizou-se apenas uma camada, que contém unidades não observáveis, e o valor de cada unidade 


\section{Gestãoe \\ Desenvolvimento}

e-ISSN: 2446-6875

p-ISSN: $1807-5436$

escondida é al guma função dos preditores. Já a camada de saída (variável categórica) contém as respostas, solvente ou insolvente. Sendo que cada neurônio de saída é uma função das unidades escondidas.

Figura 4 - Arquitetura feedforward (Modelo - MT\&D e Modelo - MT) com uma camada oculta

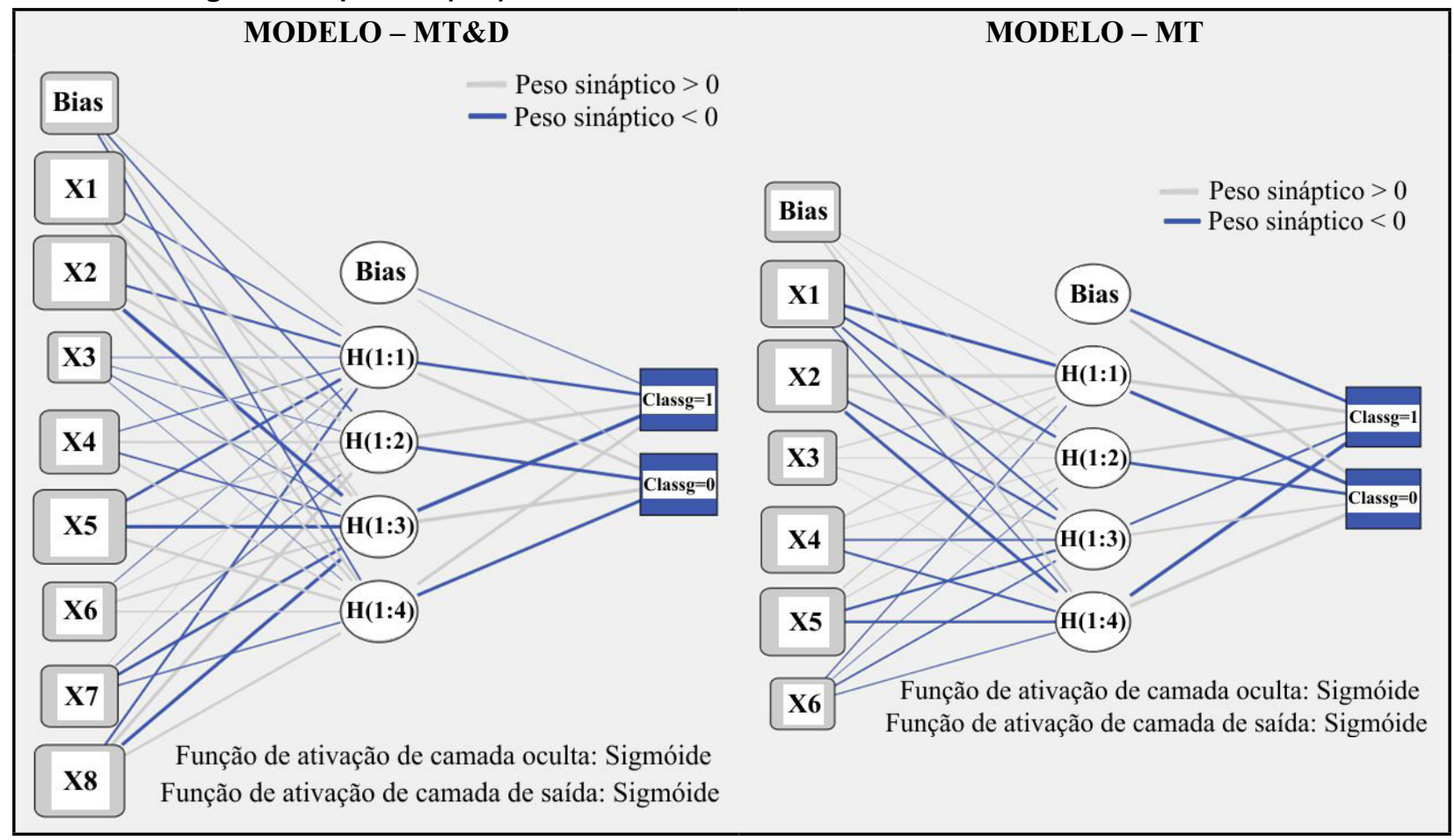

Fonte: Dados da pesquisa.

Como pode ser visto na figura acima, as conexões sinápticas de cor azul representam pesos menores do que zero (0), e as conexões sinápticas de cor cinza, os pesos maiores do que zero. Pode-se observar, também, que o tamanho de cada caixa onde estão inseridos os índices ( $X_{1}$ a $X_{8}$ e os índices de $X_{1}$ a $X_{6}$ ) representa a importância de cada um dos preditores (variável de entrada) para o modelo.

A relevância de cada índice econômico-financeiro, para os modelos gerados, pode ser mais bem compreendida na Tabela 6, onde são apresentados os índices por critério de importância e importância normalizada (percentual). A importância normalizada é simplesmente o cálculo dos valores de importância, dividido pelos maiores valores de importância e expresso em porcentagens.

Entre as variáveis do Modelo - MT que apresentaram maior relevância para a concessão de crédito estão a variável $X_{2^{\prime}}$ com $100 \%$ de representatividade, sendo essa um índice de estrutura de capital que evidencia o relacionamento entre o Disponível e o Ativo Total. Tendo como base que $X_{2}$ apresenta valores menores para o grupo de empresas insolventes, fica claro que empresas insolventes apresentam uma 


\section{Gestãoe \\ Desenvolvimento}

e-ISSN: 2446-6875

p-ISSN: $1807-5436$

disponibilidade menor do que as solventes, o que pode refletir na sua capacidade de cumprir com suas obrigações de curo prazo.

A variável $X_{5^{\prime}}$ um índice de rentabilidade que também apresentou um coeficiente significativo de $82,6 \%$, essa demonstra a relação entre o Lucro Operacional e o Lucro Bruto. Aqui, quanto maior for este indicador, mais solvente será a empresa, pois apresentará lucro gerado por sua atividade. Todavia, se a operação não gera lucro, a empresa encaminha-se para um estado de insolvência.

Tabela 6 - Importância da variável independente

\begin{tabular}{c|cc|cc}
\hline \multirow{2}{*}{} & \multicolumn{2}{|c|}{ MODELO - MT\&D } & \multicolumn{2}{c}{ MODELO - MT } \\
\cline { 2 - 5 } & Importância & Importância normalizada & Importância & Importância normalizada \\
\hline X1 & 0,172 & $90,9 \%$ & 0,207 & $78,5 \%$ \\
X2 & 0,187 & $98,9 \%$ & 0,263 & $100,0 \%$ \\
X3 & 0,009 & $4,8 \%$ & 0,072 & $27,5 \%$ \\
X4 & 0,107 & $56,7 \%$ & 0,202 & $76,6 \%$ \\
X5 & 0,189 & $100,0 \%$ & 0,217 & $82,6 \%$ \\
X6 & 0,070 & $36,9 \%$ & 0,039 & $14,7 \%$ \\
X7 & 0,093 & $49,1 \%$ & - & - \\
X8 & 0,172 & $91,0 \%$ & - & - \\
\hline
\end{tabular}

Fonte: Dados da pesquisa.

No Modelo - MT\&D, as variáveis que apresentaram maiores contribuições foram $X_{5}$ e $X_{2^{\prime}}$ citados anteriormente, essas com 100\% e 98,9\% de acurácia, respectivamente. Contudo, a contribuição do Modelo Dinâmico para a avaliação da insolvência empresarial é dada por $X_{\mathcal{g}^{\prime}}$ um índice de liquidez que apresenta 91\% de precisão para a discriminação dos grupos.

Como explana Sanvicente e Minardi (1998), o Saldo em Tesouraria é um fator relevante para prever falências no Brasil. Adiante Assaf Neto e Silva (2012) consideram que o saldo disponível funciona como uma reserva financeira da empresa, uma condição essencial para o equilíbrio financeiro da empresa assim como também uma margem de segurança para eventuais dificuldades financeiras. 0 que demonstra a importância da variável $X_{8}$ para a análise, ao melhorar o desempenho de algumas variáveis simultaneamente, tornando o modelo mais coeso.

Outro output importante do programa é o resumo do modelo. Este apresenta informações acerca dos resultados do treinamento e aplica a amostra de validação à rede encontrada, possibilitando, assim, saber o percentual de predições incorretas. 


\section{Gestãoe \\ Desenvolvimento}

e-ISSN: 2446-6875

p-ISSN: 1807-5436

A soma dos erros quadráticos é mostrada, por ter-se utilizado a função de ativação sigmoide, tanto na camada oculta como na camada de saída. Para os dois modelos, os erros quadráticos apresentam taxas baixas, sendo de 0,015 para o Modelo - MT\&D e de 0,071 para o Modelo - MT. Esta é a função de erro que a rede tenta minimizar durante o treinamento (BRAGA; CARVALHO; LUDERMIR, 2011).

Como pode ser visto, para o Modelo - MT\&D, na regra de parada utilizada, o treinamento foi interrompido porque o erro convergiu. Já para o Modelo - MT, o número de períodos foi ultrapassado sem que o Modelo conseguisse convergir o erro. Entretanto, observa-se que, nos treinamentos realizados para a obtenção do Modelo - MT, outros modelos conseguiram convergir o erro, contudo não apresentaram melhor taxa de previsões incorretas.

Para encontrar a porcentagem de previsões incorretas para o modelo gerado, utilizou-se a amostra de validação. Nota-se que, no Modelo - MT\&D, não houve previsões incorretas, todavia, o Modelo - MT apresentou um percentual de 3,1\% de previsões incorretas. Estes dados podem ser mais bem visualizados na Tabela 7, logo abaixo.

Tabela 7 - Resumo do modelo

\begin{tabular}{ll|c|c}
\hline & MODELO - MT\&D & MODELO - MT \\
\hline Treinamento & $\begin{array}{l}\text { Soma dos erros } \\
\text { quadráticos }\end{array}$ & 0,015 & 0,071 \\
\cline { 2 - 4 } & $\begin{array}{l}\text { Porcentagem de } \\
\text { previsões incorretas }\end{array}$ & $0,0 \%$ & $0,0 \%$ \\
\cline { 2 - 4 } & $\begin{array}{l}\text { Regra de parada } \\
\text { utilizada }\end{array}$ & $\begin{array}{c}\text { Critério de proporção de erro } \\
\text { de treinamento (0,001) obtido }\end{array}$ & $\begin{array}{c}\text { Número máximo de } \\
\text { períodos (100) excedido }\end{array}$ \\
\cline { 2 - 4 } & $\begin{array}{l}\text { Tempo de } \\
\text { treinamento }\end{array}$ & $0: 00: 00,00$ & $0: 00: 00,02$ \\
\hline Validação & $\begin{array}{l}\text { Porcentagem de } \\
\text { previsões incorretas }\end{array}$ & $0,0 \%$ & $3,1 \%$ \\
\hline Variável dependente: Classg & & \\
\hline
\end{tabular}

Fonte: Dados da pesquisa.

Os resultados práticos de se utilizar a rede neural artificial podem ser vistos na Tabela 8, na qual, para cada caso classificado como sim, o neurônio é ativado com função de ativação sigmoide, isto é, quando o seu limiar atinge valor igual ou superior a 0,5.

No entanto, na validação cruzada, as células que se encontram na diagonal representam previsões corretas, e as células fora da diagonal são predições incorretas. Como demonstrado (Tabela 8), para o 
Modelo - MT\&D e para o Modelo - MT, a amostra de treinamento obteve $100 \%$ de acerto, classificando os 34 casos (de empresas) solventes como solventes e os 34 insolventes como insolventes.

Já para a amostra de validação, o Modelo - MT\&D convergiu em 100\% de acerto global, enquanto o Modelo - MT apresentou erro Tipo II, classificando um caso que era solvente como insolvente. O que na prática acarretaria em deixar de emprestar recursos a uma empresa solvente julgando que esta é insolvente, deixando assim de obter os bônus da transação. O Modelo - MT apresentou acerto global de $96,9 \%$.

Neste sentido, os modelos parecem atender a suas finalidades de identificar empresas insolventes durante a concessão de crédito, evitando que ocorra o pior que é o erro Tipo I, isto é, realizar empréstimo a uma empresa insolvente considerando que ela é solvente e incorrer em perdas financeiras.

Tabela 8 - Percentual de classificação das redes neurais artificiais

\begin{tabular}{|c|c|c|c|c|c|c|c|}
\hline \multirow[b]{2}{*}{ Amostra } & \multirow[b]{2}{*}{ Observado } & \multicolumn{3}{|c|}{ Previsto para MODELO - MT\&D } & \multicolumn{3}{|c|}{ Previsto para MODELO - MT } \\
\hline & & Solvente & Insolvente & $\begin{array}{l}\text { Percentual } \\
\text { correto }\end{array}$ & Solvente & Insolvente & $\begin{array}{c}\text { Percentual } \\
\text { correto }\end{array}$ \\
\hline \multirow{3}{*}{ Treinamento } & Solvente & 34 & 0 & $100 \%$ & 34 & 0 & $100 \%$ \\
\hline & Insolvente & 0 & 34 & $100 \%$ & 0 & 34 & $100 \%$ \\
\hline & $\begin{array}{l}\text { Porcentagem } \\
\text { global }\end{array}$ & $50 \%$ & $50,0 \%$ & $100 \%$ & $50 \%$ & $50 \%$ & $100 \%$ \\
\hline \multirow{3}{*}{ Validação } & Solvente & 16 & 0 & $100 \%$ & 15 & 1 & $93,8 \%$ \\
\hline & Insolvente & 0 & 16 & $100 \%$ & 0 & 16 & $100 \%$ \\
\hline & $\begin{array}{l}\text { Porcentagem } \\
\text { global }\end{array}$ & $50 \%$ & $50,0 \%$ & $100 \%$ & $46,9 \%$ & $53,1 \%$ & $96,9 \%$ \\
\hline
\end{tabular}

Variável dependente: Classg

Fonte: Dados da pesquisa.

Por fim, são apresentadas as estimativas de parâmetro para Modelo - MT\&D, que é formado pelas variáveis do modelo tradicional e pelo modelo dinâmico de análise financeira, devido ao fato de este ter apresentado melhor porcentual e classificação em relação ao Modelo - MT, que era composto apenas por índices do modelo tradicional de análise (Tabela 9).

A integração entre visão estática da análise tradicional baseada na solvência e a visão sistêmica da análise dinâmica focada na liquidez empresarial, proposta por Brasil e Brasil (2008), apresentou resultados promissores para análise do risco de crédito. Partindo dos estudos de Fleuriet, Kehdy e Blanc (1978; 2003), Assaf Neto e Silva (2012), Sanvicente e Minardi (1998) e Carvalho (2004), encontra-se resultados que 


\section{Gestãoe \\ Desenvolvimento}

e-ISSN: 2446-6875

p-ISSN: $1807-5436$

apontam para a importância do modelo dinâmico e do Efeito Tesoura para identificar problemas futuros de insolvência.

Tabela 9 - Estimativas do parâmetro (Matrizes de coeficientes ou pesos de conexão)

\begin{tabular}{|c|c|c|c|c|c|c|c|}
\hline \multirow[b]{3}{*}{ Previsor } & & \multicolumn{6}{|c|}{ Previsto } \\
\hline & & \multicolumn{3}{|c|}{ Camada oculta 1} & \multicolumn{3}{|c|}{ Camada de saída } \\
\hline & & $\mathrm{H}(1: 1)$ & $H(1: 2)$ & $H(1: 3)$ & $\mathrm{H}(1: 4)$ & [Classg=0 & [Classg=1] \\
\hline \multirow[t]{9}{*}{ Camada de entrada } & (Propensão) & 0,893 & $-0,920$ & 1,430 & $-1,012$ & & \\
\hline & $\mathrm{X} 1$ & $-0,866$ & 1,937 & 4,377 & 1,894 & & \\
\hline & $x 2$ & $-1,743$ & 1,975 & $-6,123$ & 1,552 & & \\
\hline & X3 & $-0,043$ & $-0,295$ & $-0,397$ & $-0,040$ & & \\
\hline & $\times 4$ & $-0,595$ & 1,544 & $-0,957$ & 1,404 & & \\
\hline & $\times 5$ & $-2,201$ & 1,398 & $-4,308$ & 2,155 & & \\
\hline & $x 6$ & $-0,318$ & 0,536 & 1,628 & 0,798 & & \\
\hline & $x 7$ & 0,119 & $-0,613$ & $-2,459$ & $-0,722$ & & \\
\hline & X8 & $-1,624$ & 2,942 & $-3,866$ & 1,802 & & \\
\hline \multirow[t]{5}{*}{ Camada oculta 1} & (Propensão) & & & & & $-0,397$ & 0,370 \\
\hline & $H(1: 1)$ & & & & & $-2,586$ & 2,719 \\
\hline & $H(1: 2)$ & & & & & 3,094 & $-2,919$ \\
\hline & $H(1: 3)$ & & & & & $-9,650$ & 9,585 \\
\hline & $H(1: 4)$ & & & & & 2,787 & $-2,889$ \\
\hline
\end{tabular}

Legenda: A Propensão equivale ao Bias, isto é, um peso sináptico, como demonstrado no do neurônio artificial.

Fonte: Dados da pesquisa.

Observa-se, na Tabela 9, que, quando a "Classg=0" for ativada, a empresa será considerada solvente pelo modelo e, sendo assim, merecedora de crédito junto à instituição. Já quando a "Classg=1" for ativada, a empresa será considerada insolvente, ficando esta impossibilitada de tomar crédito junto à instituição credora.

Por conseguinte, quando implementado o modelo de redes neurais artificiais, pode-se diminuir custos referentes tanto à análise de risco de crédito como, ainda, à efetiva redução da inadimplência. Outrossim, auxiliar no processo decisório do gerente ou analista de risco de crédito ao fornecer uma metodologia robusta de classificação entre empresas solventes e empresas insolventes. 


\section{CONCLUSÕES}

Em virtude dos vários aspectos observados para o embasamento e a construção do presente modelo, pode-se concluir que as redes neurais artificiais são capazes de prever a solvência e a insolvência de empresas, minimizando, desta forma, as perdas para as instituições credoras. Observou-se que a definição dos índices econômico-financeiros, a partir do modelo tradicional e do modelo dinâmico de análise financeira, demonstrou resultados apropriados.

As variáveis mais importantes para o trabalho foram: $X_{2^{\prime}}$ um índice de estrutura de capital, que representa qual a liquidez imediata possui o patrimônio da empresa (ativo total), sendo que, neste caso, as empresas insolventes apresentaram índices menores do que as empresas solventes. O Modelo - MT apresentou, para esta variável, 100\% de importância. Já para o Modelo - MT\&D, este índice obteve 98,9\% de importância.

Outra variável importante para os dois modelos foi o índice $X_{5^{\prime}}$ que é um índice de rentabilidade. Entretanto, aqui, pode ser especificado como sendo um demonstrativo de rentabilidade bruta, ao comparar qual é o percentual de lucro gerado pela operação da empresa, dividindo o lucro operacional pelo lucro bruto.

Neste sentido, quanto maior for este indicador, mais solvente será a empresa, pois apresentará um maior lucro da operação, ou seja, lucro gerado por sua atividade fim. Todavia, se a operação não gera lucro, a empresa encaminha-se para um estado de insolvência, pois a empresa não estará gerando lucro que resulte no aumento de seu patrimônio. Para o Modelo - MT, o índice $X_{5}$ obteve representatividade de $82,6 \%$, enquanto para o Modelo - MT\&D alcançou $100 \%$ de importância.

No modelo - MT\&D, ao se utilizar as variáveis $X_{7}$ e $X_{8}$ do modelo dinâmico de análise financeira, ficou claro que o modelo de avaliação de crédito apresentou mais ênfase à variável $X_{\mathcal{8}^{\prime}}$ com classificação de importância de $91 \%$, contra $49,1 \%$ da variável $X_{7}$

Este fato pode ser interpretado pela seguinte ótica: apesar das duas variáveis $\left(X_{7}\right.$ e $\left.X_{8}\right)$ serem índices de liquidez, a variável $X_{8}$ está relacionada com as operações financeiras da empresa, e estas acarretam em juros, que são maiores para empresas insolventes.

$\mathrm{O}$ ativo financeiro da empresa pode ser encarado como "quanto maior melhor". Isto por causa dos retornos gerados, viabilizando o aumento de patrimônio (capital - juros recebidos). Em contrapartida, o passivo circulante financeiro é interpretado "quanto menor melhor", ou seja, quanto menor este for, menos se pagará de juros sobre o passivo financeiro. 
Sendo assim, a amostra, em sua maioria, apresentou valores baixos (negativos) para as empresas insolventes e valores maiores (positivos) para empresas solventes. Cabe observar que o fato de o valor calculado ser negativo ou positivo, por si só, não define o estado de insolvência ou solvência da instituição.

Já o cálculo da variável $X_{7}$ não envolve juros e, no caso do passivo, em particular, no geral ainda se pode negociar prazo em contas, como a de fornecedor, ao menos no princípio do processo de desintegração do patrimônio. Contudo, a importância da variável $X_{8}$ para a análise também pode ser percebida pela melhora do desempenho do modelo de análise de crédito e pela melhora de algumas variáveis (índices), simultaneamente, tornando o modelo como um todo mais coeso.

A comparação dos Modelos - MT\&D e Modelo - MT visou a avaliar a integração do modelo dinâmico ao modelo tradicional e também a verificar a contribuição dos índices pertencentes ao modelo dinâmico para o modelo gerado. Por este método, foi possível comprovar a contribuição das variáveis do modelo dinâmico para a análise de insolvência com vista à concessão de crédito.

Observa-se, entretanto, que em nenhuma das configurações de redes neurais que não possuía as variáveis do modelo dinâmico pode-se atingir uma classificação de 100\%, embora a margem de acerto seja bastante elevada sem as variáveis do modelo dinâmico. Com relação à amostra utilizada, pode-se concluir que a rede neural é eficiente em relação aos índices testados, ao atingir 100\% de acurácia, superando a análise discriminante efetuada por Carvalho (2004), que obteve grau de precisão de 96,0\%.

Em decorrência dos procedimentos delimitados para essa pesquisa, utilização das redes neurais no setor comercial com apenas oito variáveis, indica-se como ampliação dos estudos um arcabouço maior de variáveis tanto do modelo dinâmico como do modelo tradicional de análise financeira. Além da comparação de ferramentas para modelagem, tais como análise discriminante, regressão logística, árvore de decisão, análise de conglomerados (clusters analysis) e lógica nebulosa (fuzzy logic), entre outras.

Utilizar modelagem para avaliar outros setores da economia, a fim de saber quais características estes apresentam em suas demonstrações financeiras, também poderia ser de grande valia, sendo que traria maior clareza sobre as especificações que envolvem a análise de crédito, em um determinado ramo de atividade.

\section{REFERÊNCIAS}

ALTMAN, Edward L. Financial Ratios, Discriminant Analysis and the Prediction of Corporate Bankruptcy. The Journal of Finance, v. 23, n. 4, 589-609 p., sept., 1968.

ALTMAN, Edward L.; BAIDYA, Tara K. N.; DIAS, Luiz Manoel Ribeiro. Previsão de problemas financeiros em empresas. Revista de Administração de Empresas - RAE, v. 19 (1), 17-28 p., jan./mar., 1979. 


\section{Gestãoe \\ Desenvolvimento}

e-ISSN: 2446-6875

p-ISSN: $1807-5436$

ASSAF NETO, Alexandre. Finanças corporativas e valor. 5. ed. São Paulo: Atlas, 2010. 726 p.

ASSAF NETO, Alexandre. SILVA, César Augusto Tibúrcio. Administração do Capital de Giro. 4. ed. São

Paulo: Atlas, 2012. 269 p.

BEAVER, W. H. Financial ratios predictors of failure. Journal of Accounting Research, v. 4, 1967, p. 71111.

BRAGA, A. P.; CARVALHO, A. C. P. L. F.; LUDERMIR, T. B. Redes Neurais Artificiais: Teoria e Aplicações. 2. ed. Rio de Janeiro: LTC, 2011. 226 p.

BRASIL, Haroldo Vinagre; BRASIL, Haroldo Guimarães. Gestão Financeira das Empresas: um modelo dinâmico. 4. ed. Rio de janeiro: Qualitymark, 2008. 163 p. (5ª Reimpressão).

BRASIL. Congresso Nacional. Lei n. 11.101 de 9 de fevereiro de 2005. Regula a recuperação judicial, a extrajudicial e a falência do empresário e da sociedade empresaria. DOU, edição extra, DF, 9 fev. 2005. Disponivel em: <http://www.planalto.gov.br/ccivil_03/_Ato2004-2006/2005/Lei/L11101.htm\#art200>. Acesso em: 21 set. 2012.

BRIGHAM, Eugene F.; EHRHARDT, Michael C. Administração Financeira: Teoria e Prática. 13. ed. São Paulo: Cengage Learning, 2012. 1113 p.

CARVALHO, Alfredo Tertuliano de. Modelo de previsão de insolvência para empresas comerciais. 2004, 129 p. Dissertação (Mestrado em Engenharia de Produção), Programa de Pós-Graduação em Engenharia de Produção da Universidade Federal de Santa Catarina, Florianópolis, 2004. Disponível em: <http:// www.tede.ufsc.br/teses/PEPS4777.pdf>. Acesso em: 25 maio 2012.

CARVALHO, D. W. O direito e o gerenciamento dos riscos ambientais. Revista Gestão e Desenvolvimento, v. 4, n. 1, p. 101-107, 2007.

CASTRO JUNIOR, F. H. F. Previsão de insolvência de empresas brasileiras usando análise discriminante, regressão logística e redes neurais. 2003. 169f. 2003. Tese de Doutorado. Dissertação (Mestrado em Administração). Faculdade de Economia, Administração e Contabilidade. São Paulo: Universidade de São Paulo.

DURAND, D. Risk elements in consumer installment lending. Studies in consumer installment financing. National Bureau of Economic Research, Inc., New York, v. 8, 1941.

FARIA, R. B.; SANTOS, D. F. L. O crédito rural no Brasil: o perfil das pesquisas acadêmicas. Revista Gestão e Desenvolvimento, v. 11, n. 2, p. 148-165, 2014. 


\section{Gestãoe \\ Desenvolvimento}

e-ISSN: 2446-6875

p-ISSN: $1807-5436$

FISHER, R. A. The Use of Multiple Measurements in Taxonomic Problems. Annals of Eugenic, v. 7, n. 2, p. 179-188, 1936.

FLEURIET, M.; KEHDY, R.; BLANC, G. A dinâmica financeira das empresas brasileiras: um método de análise, orçamento e planejamento financeiro. Belo Horizonte: Fundação Dom Cabral, 1978. 181 p.

FLEURIET, M.; KEHDY, R.; BLANC, G. 0 Modelo Fleuriet: a dinâmica financeira das empresas brasileiras: um método de análise, orçamento e planejamento financeiro. 3. ed. Rio de Janeiro: Campus, 2003. 169 p.

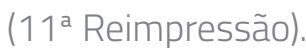

GOUVÊA, M. A.; GONÇALVES, E. B.; MANTOVANI, D. M. N. Análise de Risco de Crédito com Aplicação de Regressão Logística e Redes Neurais. Contabilidade Vista \& Revista, v. 24, n. 4, p. 96-123, 2015.

KANITZ, Stephen Charles. Como prever falências de empresas. Revista Negócios em Exame (Revista EXAME), dez. 1974. 95-102 p. Disponivel em: <http://pt.scribd.com/doc/61123852/EXAME-ComoPreverFalenciaEmpresa-Kanitz>. Acesso em: 11 out. 2012.

LIMA, F. G.; PERERA, L. C. J.; KIMURA, H.; SILVA FILHO, A. C. Aplicação de Redes Neurais na Análise e na Concessão de Crédito ao Consumidor. RAUSP. Revista de Administração, v. 44, p. 34-45, 2009.

MÁRIO, Poueri do Carmo. Contribuição ao estudo da solvência empresarial: uma análise de modelos de previsão - estudo exploratório aplicado em empresas mineiras. 2002. 209 p. Dissertação (Mestrado em Controladoria e Contabilidade: Contabilidade) - Faculdade de Economia, Administração e Contabilidade, Universidade de São Paulo, São Paulo, 2002. Disponível em: <http://www.teses.usp.br/teses/disponiveis/12/12136/tde-06012006-152208/>. Acesso em: 14 set. 2012.

MARTINS, Márcio Severo; GALLI, Oscar Claudino. A previsão de insolvência pelo modelo Cox: uma aplicação para a análise de risco de companhias abertas brasileiras. Revista Eletrônica de Administração, v. 13, n. 1, p. 231-248, 2007.

MATIAS, Alberto Borges. Contribuição às técnicas de análise financeira: um modelo de concessão de crédito. 1978. 101p. Monografia - Trabalho apresentado ao Departamento de Administração da Faculdade de Economia, Administração e Contabilidade da USP, São Paulo, 1978. Disponível em: <http://www. cepefin.com.br/publicados_pdf/contribuicao_tecnicas_analise_financeira_modelo_concessao_credito_monografia.pdf>. Acesso em: 06 jun. 2012.

MCCULLOCH, Warren S.; PITTS, Walter. A Logical Calculus of the Ideas Immanent in nervous Activity. Bulletin of Mathematical Biophysics, v. 5, 115-133 p., 1943. Disponivel em: <http://www.springerlink.com/ content/61446605110620kg/fulltext.pdf>. Acesso em: 28 out. 2012. 


\section{Gestãoe \\ Desenvolvimento}

e-ISSN: 2446-6875

p-ISSN: $1807-5436$

OHLSON, J. A. Financial ratios and the probabilistic prediction of bankruptcy. Journal of Accounting Research, $18(1), 1980$, p.109-131.

PEREIRA, José Manuel; DOMíngueZ, Miguel Á. Crespo; OCEJO, José L. Sáez. Modelos de Previsão do Fracasso Empresarial: Aspectos a considerar. Revista de Estudos Politécnicos (Polytechnical Studies Review), v. 4, n. 7, 111-148 p., jun. 2007. Disponivel em: <http://www.scielo.oces.mctes.pt/pdf/tek/n7/ v4n7a05.pdf>. Acesso em: 02 set. 2012.

SABATO, G. Modelos de Scoring de Risco de Crédito. Revista Tecnologia de Credito, n. 68, 2009, p. 2947.

SANVICENTE, Antônio Zoratto; MINARDI, Andrea Maria Accioly Fonseca. Identificação de indicadores contábeis significativos para previsão de concordata de empresas. Instituto Brasileiro de Mercado de Capitais, Working Paper, Out. 1998. Disponivel em: <http://risktech.com.br/PDFs/indicadores_concordata.pdf>. Acesso em: 05 jun. 2012.

SCHRICKEL, Wolfgang Kurt. Análise de crédito: concessão e gerencia de empréstimos. 5. ed. São Paulo: Atlas, 2000. 353 p.

SILVA, José Pereira da. Análise financeira das empresas. 11. ed. São Paulo: Atlas, 2012. 585 p.

SILVA, José Pereira da. Gestão e Análise de Risco de Crédito. 6. ed. São Paulo: Atlas, 2008. 421 p.

TAM, Kar Yan. Neural network models and the prediction of bank bankruptcy. Omega, v. 19, n. 5, p. 429445, 1991.

TIMM, L. B. Superendividamento: reflexões sobre aplicações do direito do consumidor. Revista Gestão e Desenvolvimento, v. 2, n. 2, p. 87-93, 2005. 